\title{
Case Report: Primary squamous cell carcinoma of the bladder secondary to chronic renal fungal ball and recurrent
} polymicrobial urinary tract infections. [version 1; peer review: 1 approved, 1 approved with reservations]

\author{
Andrew Keller ${ }^{1}$, Benjamin Shepherd ${ }^{2}$, Arief Mulyadi ${ }^{1}$, Ahmad Ali ${ }^{1}$ \\ 1Department of Urology, Ipswich General Hospital, Ipswich, Queensland, 4305, Australia \\ 2Department of Anatomical Pathology, Princess Alexandra Hospital, Brisbane, Queensland, 4102, Australia
}

V1 First published: 01 Apr 2015, 4:84
https://doi.org/10.12688/f1000research.6307.1

Latest published: $01 \mathrm{Apr} 2015, \mathbf{4 : 8 4}$

https://doi.org/10.12688/f1000research.6307.1

\section{Abstract}

\section{Introduction}

Squamous cell carcinoma (SCC) of the bladder is a rare malignancy in Western countries accounting for only $5 \%$ of all primary bladder cancers. Chronic irritation is the predominant risk factor, with chronic infections, bladder stones and long term catheterisation common precursors. The highest incidence of SCC occurs in patients with spinal cord injuries who rely on indwelling or self-catheterisation for bladder drainage. We report a case of primary SCC of the bladder secondary to a fungal ball located in the renal pelvis.

\section{Case report}

A 72 year-old lady was referred to our unit for further investigation of recurrent polymicrobial urinary tract infections associated with intermittent flank pain and complicated by sepsis. Investigations into the cause for her recurrent urinary tract infections identified a mass in her left renal pelvis. Pyeloscopy demonstrated no tumour, but a fungal ball. Attempts to clear the fungal ball via pyeloscopy resulted in recurrent intensive care unit (ICU) admission for urosepsis. Several months after her last pyeloscopy she returned with haematuria. Cystoscopy at this time revealed a large bladder mass. Biopsy revealed primary SCC of the bladder invading muscle. At cystectomy the mass had invaded pubic bone and was unresectable and a palliative ileal conduit was formed. The patient passed away less than 4 months following diagnosis.

\section{Conclusion}

We report what we believe to be the first case of primary SCC of the bladder secondary to a renal pelvis fungal ball. Despite frequent surveillance of her urinary tract the tumour developed rapidly and was unresectable at diagnosis.

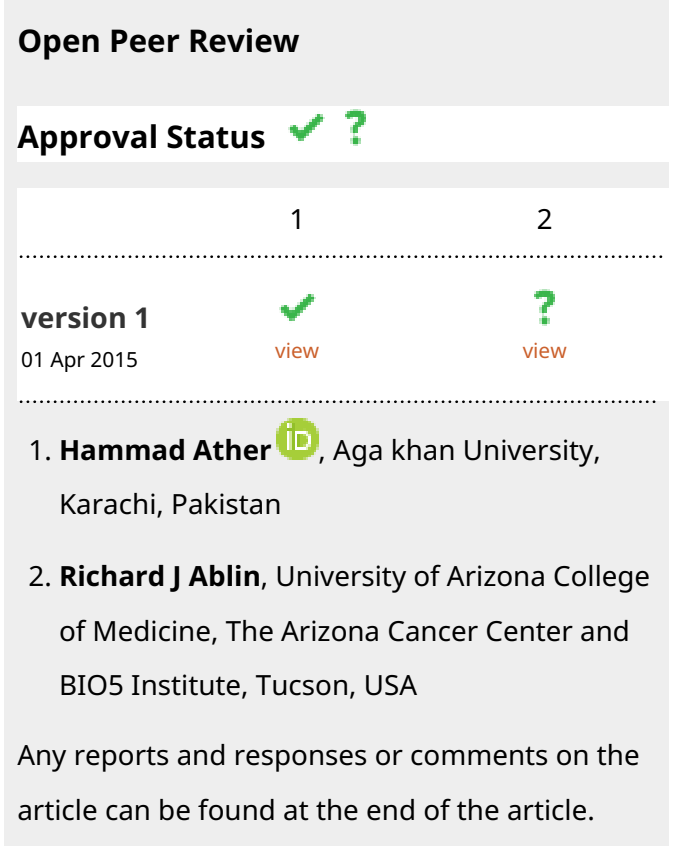


Keywords

Urinary bladder cancer, Squamous cell carcinoma, Non-urothelial

bladder cancer, Fungal ball

Corresponding author: Andrew Keller (andrewthomaskeller@gmail.com)

Competing interests: No competing interests were disclosed.

Grant information: The author(s) declared that no grants were involved in supporting this work.

Copyright: $\odot 2015$ Keller A et al. This is an open access article distributed under the terms of the Creative Commons Attribution License, which permits unrestricted use, distribution, and reproduction in any medium, provided the original work is properly cited. Data associated with the article are available under the terms of the Creative Commons Zero "No rights reserved" data waiver (CC0 1.0 Public domain dedication).

How to cite this article: Keller A, Shepherd B, Mulyadi A and Ali A. Case Report: Primary squamous cell carcinoma of the bladder secondary to chronic renal fungal ball and recurrent polymicrobial urinary tract infections. [version 1; peer review: 1 approved, 1 approved with reservations] F1000Research 2015, 4:84 https://doi.org/10.12688/f1000research.6307.1

First published: $01 \mathrm{Apr}$ 2015, 4:84 https://doi.org/10.12688/f1000research.6307.1 


\section{Introduction}

Squamous cell carcinoma (SCC) of the bladder is a rare malignancy in Western countries, accounting for only about $5 \%$ of all primary bladder cancers ${ }^{1}$. Chronic irritation is the predominant risk factor, with recurrent infections, bladder stones and long term catheterisation common precursors, and the highest incidence occurring in patients with spinal cord injuries who rely on indwelling or self-catheterisation for bladder drainage ${ }^{2,3}$. In the Middle East and Northern Africa, where schistosomiasis is endemic, the incidence is much higher, with SCC being the predominant subtype of bladder cancer ${ }^{4}$. We report a case of primary SCC of the bladder secondary to a fungal ball located in the renal pelvis.

\section{Case report}

A 72 year-old Caucasian lady was referred to our unit for further investigation of recurrent polymicrobial urinary tract infections (UTI) complicated by sepsis and associated with intermittent left flank pain. An ultrasound performed by the treating team revealed a poorly defined, poorly vascularised mass in the lower pole calyx of her left kidney associated with moderate ipsilateral hydronephrosis.

The patient had extensive medical co-morbidities including chronic renal impairment, ischaemic heart disease with unstable angina, aortic stenosis and mitral regurgitation in addition to a previous cerebrovascular event (CVA) 8 years prior with residual left sided weakness and blindness, and a known but unclipped middle cerebral artery aneurysm.

We arranged further investigations including a mercaptoacetyltriglycine (MAG 3) renogram, computerised tomography (CT) of her renal tracts and urine cytology. The MAG3 renogram demonstrated obstructed drainage of urine from the left renal pelvis. CT again demonstrated left-sided hydro-nephrosis, with a poorly defined mass in the lower pole calyx, with no obvious contrast enhancement. Urine cytology was negative for malignancy with only nonspecific inflammatory changes present.

Cystoscopy, retrograde pyelogram (RGP) and insertion of ureteric stent were arranged to further investigate her renal mass and hydronephrosis. Cystoscopic examination of the bladder was unremarkable. RGP demonstrated a "moth-eaten" left lower pole filling defect (Figure 1). Washings from the renal pelvis were taken via ureteric catheter. A ureteric stent was placed and she was discharged on the same day.

The day following her procedure she presented to the emergency department with urosepsis. Her urine and blood failed to culture a causative organism and she was subsequently discharged on oral trimethoprim $300 \mathrm{mg}$ daily for seven days after clinical improvement following intravenous piperacillin/tazobactam, $4.1 \mathrm{~g}$ three times daily.

Urine cytology from operative renal pelvis washings were again inconclusive, with non-specific inflammatory changes only, and flexible pyeloscopy was arranged two weeks later in order to better assess her renal mass. The bladder was again unremarkable on cystoscopic examination. Flexible pyeloscopy demonstrated a poorly defined mass in the lower calyx. Visualisation of the mass was poor

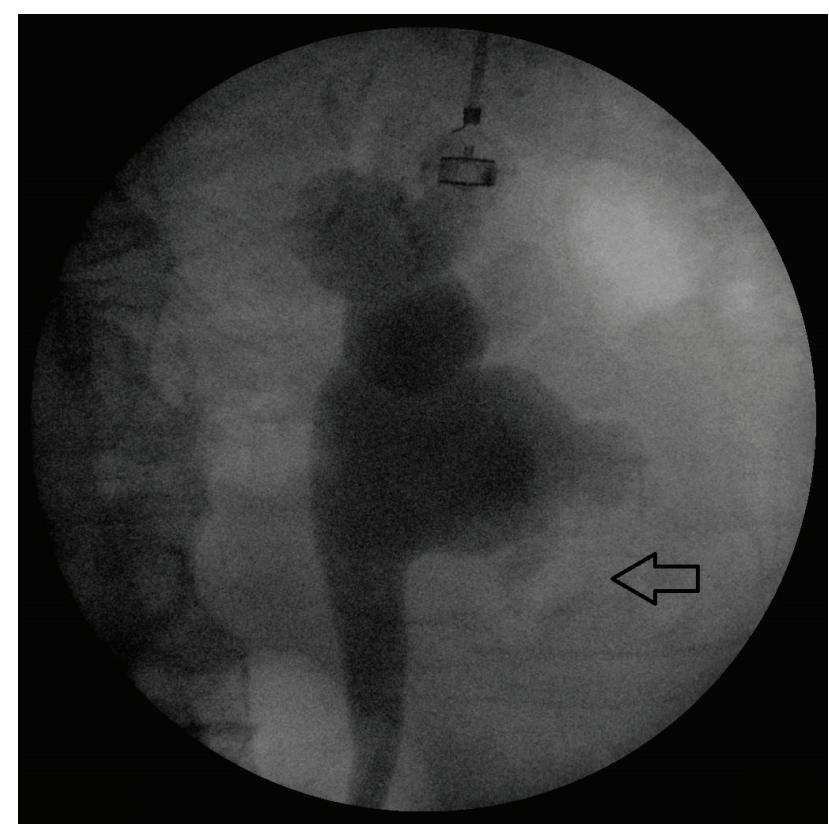

Figure 1. Retrograde Pyelogram demonstrating patchy filling defect in the lower pole calyx of the left kidney (arrow).

due to debris in the renal pelvis and contact bleeding. Washings and tissue biopsies were retrieved and her ureteric stent was replaced. The patient was discharged the following day on oral norfloxacin 400mg twice daily for seven days.

Biopsies and washings following pyeloscopy demonstrated no evidence of malignancy, but fungal elements were identified on microscopy. Re-look pyeloscopy was arranged in two weeks to exclude urothelial malignancy as visualisation of the mass at the previous pyeloscopy had been poor.

At repeat flexible pyeloscopy we again saw no macroscopic evidence of a renal pelvis tumour. However, a white plaque was seen extending over the lower pole calyces suggestive of a fungal ball. After subtotal removal of the fungal plaque with an endoscopic basket, a temporary ureteric catheter was placed. Post-operatively, the patient became haemodynamically unstable and unresponsive to fluid resuscitation and was transferred to the ICU. Treatment with teicoplanin (800mg twice daily loading dose, following by $400 \mathrm{mg}$ once daily dosing) and piperacillin/tazobactam (4.1g three times daily) was initiated due to her history of polymicrobial UTI. Intravenous caspofungin (70mg once daily loading dose, $50 \mathrm{mg}$ once daily maintenance) was used in addition to cover for possible fungaemia. Vasopressor support necessitated ICU stay for three days prior to a further seven days of intravenous piperacillin/tazobactam on the surgical ward. She was discharged on oral fluconazole $200 \mathrm{mg}$ once daily for two weeks.

As a result of urosepsis repeatedly complicating any urological procedure, the patient remaining currently asymptomatic and her multiple medical comorbidities, we decided to manage her fungal ball conservatively and no further procedures were planned at this stage. 
After several uneventful months, the patient represented with a further episode of urosepsis again unresponsive to fluid resuscitation. A further extended stay in ICU on vasopressor support was required. CT of the urinary tract at this time demonstrated recurrent mild left hydronephrosis and reappearance of debris in the lower pole calyces. A ureteric stent was placed in case upper tract obstruction had precipitated her sepsis. In view of her continued septic episodes and recurrence of her fungal ball, we decided in conjunction with the patient to prepare for an elective simple nephrectomy. Infectious diseases prescribed oral voriconazole $200 \mathrm{mg}$ twice daily to be continued prophylactically on discharge until her planned nephrectomy which was tentatively scheduled in 1 months' time.

Prior to her planned nephrectomy she was re-admitted for a further episode of urosepsis, this time complicated by the new symptom of macroscopic haematuria with passage of multiple clots. After failed conservative management of her haematuria with bladder irrigations, flexible cystoscopy was performed to identify the source of ongoing bleeding. A large ulcerated erythematous mass was found, adjacent to her left ureteric orifice (Figure 2 and Figure 3). CT confirmed an enhancing bladder mass $5 \mathrm{~cm}$ in diameter, arising from the left wall of her bladder (Figure 4). Resection of bladder tumour was performed and confirmed a pure squamous cell carcinoma of the bladder with invasion into muscularis propria (Figure 5, Figure 6, Figure 7 and Figure 8).

The patient was booked for a radical cystectomy and formation of an ileal conduit. At operation the tumour was found to have invaded pubic symphysis and was deemed unresectable. The planned cystectomy was aborted and instead a palliative urinary diversion was created. The patient was reviewed by medical and

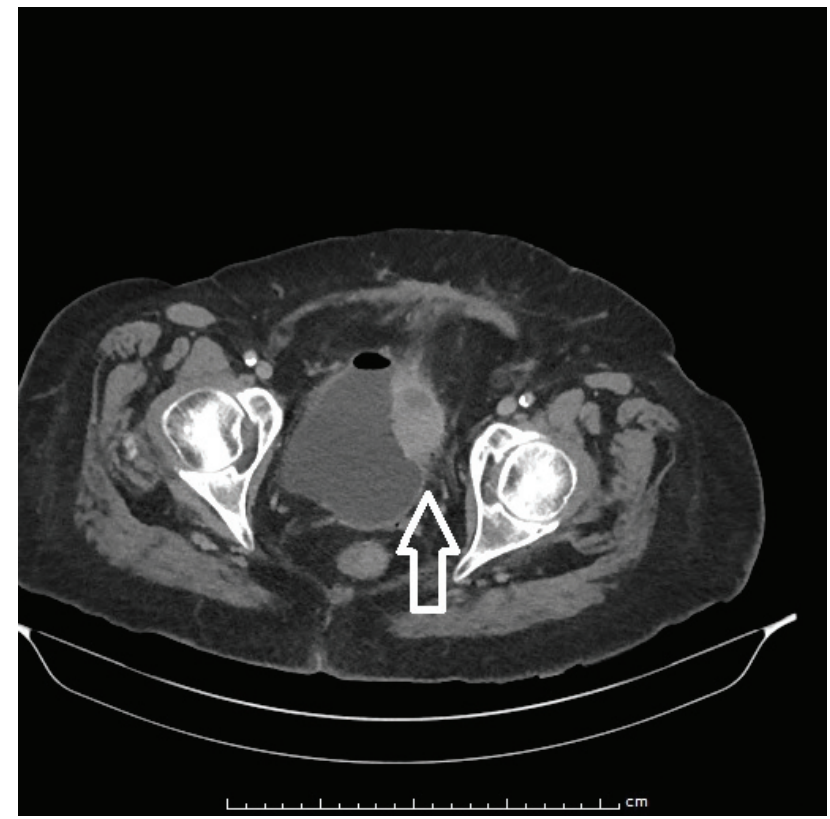

Figure 2. Contrast-enhanced axial CT scan of pelvis demonstrating an enhancing soft tissue mass arising from the left lateral wall of the urinary bladder (arrow).

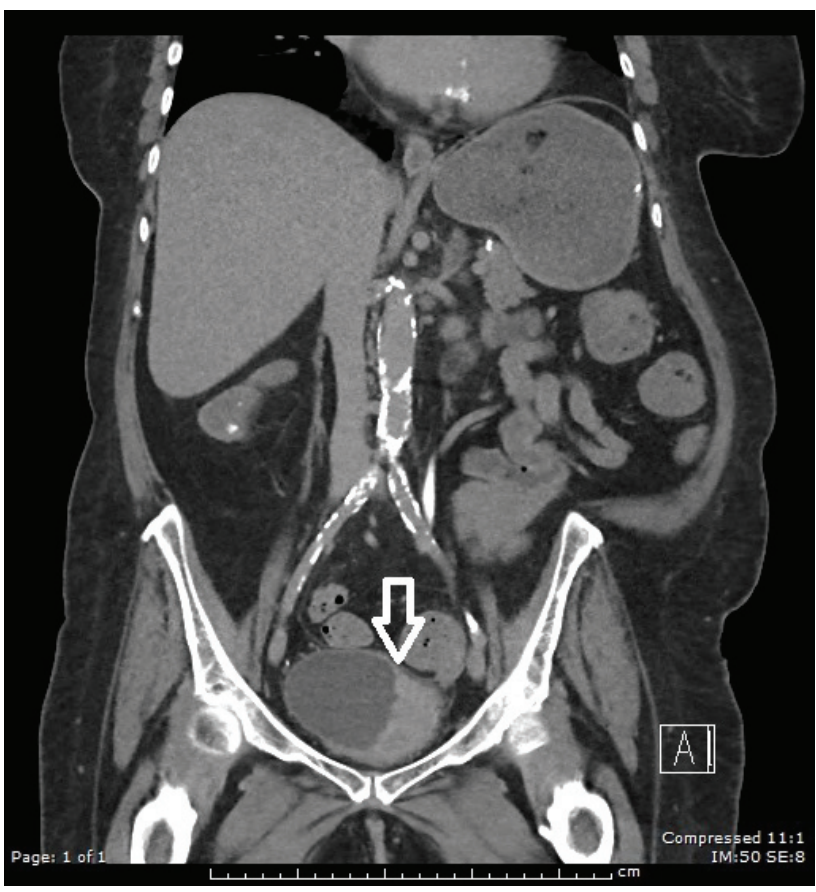

Figure 3. Contrast-enhanced coronal CT scan of abdomen and pelvis demonstrating a large contrast enhancing soft tissue mass arising from the left lateral bladder wall and extending from base of bladder to dome.

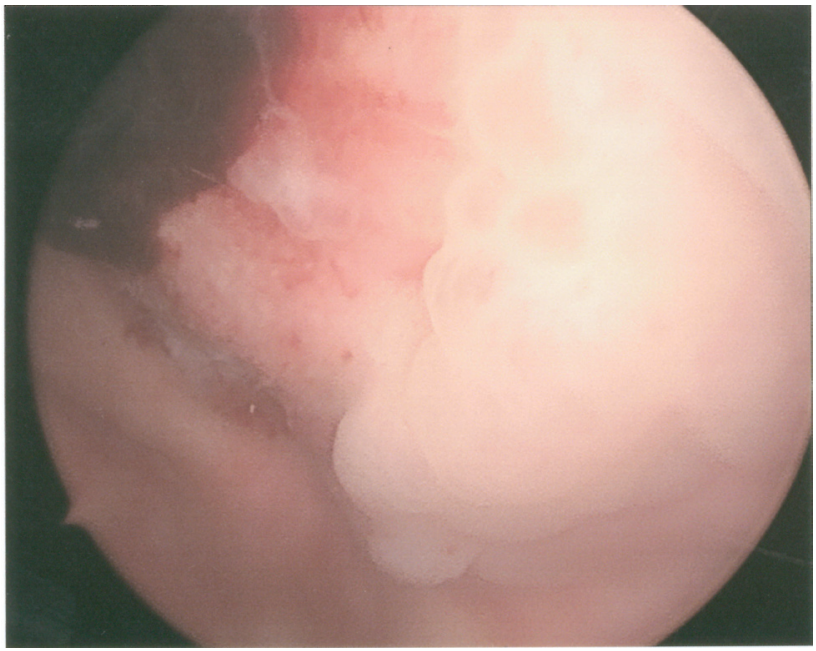

Figure 4. Operative photo. Cystoscopic examination revealed a large irregular ulcerated bladder mass with adherent blood clot.

radiation oncology in regards to her suitability for adjuvant chemoradiotherapy but the consensus was that she would not benefit from further aggressive treatment.

One month post-operatively she developed recurrent bleeds from her bladder with difficulty and much discomfort expelling the clots. She received two fractions of palliative radiotherapy to her bladder. 


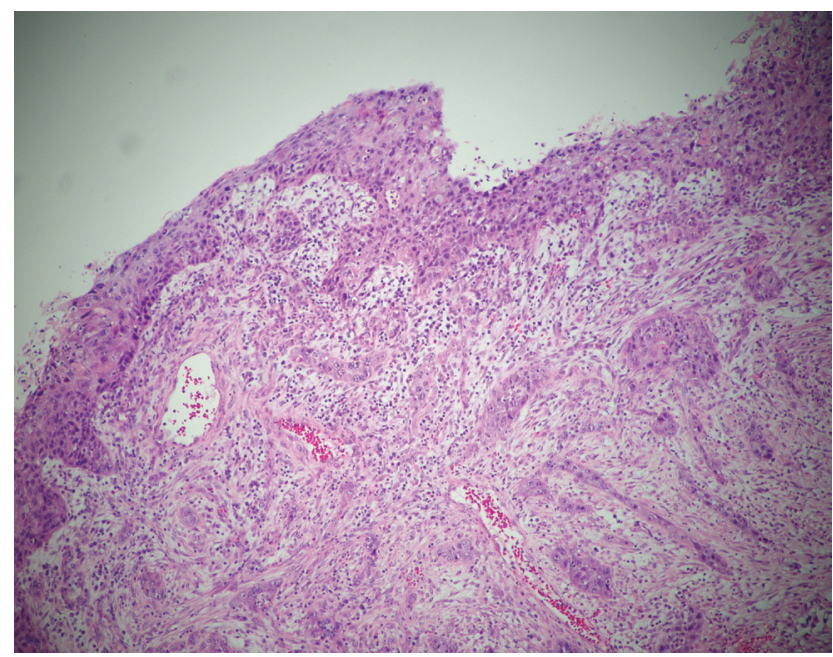

Figure 5. Haematoxylin and eosin stain, 100x magnification. Squamous carcinoma in situ is seen overlying a focus of SCC which has invaded into the lamina propria.

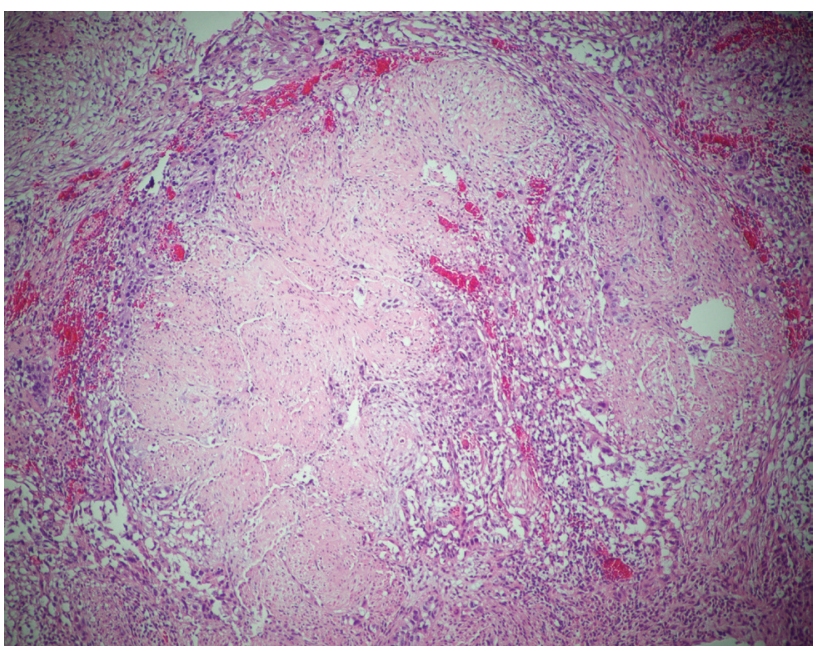

Figure 6. Haematoxylin and eosin stain, $100 \times$ magnification. SCC is here seen invading into the muscularis propria.

Prior to receiving further planned doses she was again admitted to hospital with another urinary tract infection and further bladder haemorrhage. Whilst in hospital she continued to deteriorate despite antibiotics and after discussion with the patient and her family, comfort cares were initiated. She passed away just over three months following her urinary diversion and less than four months following her diagnosis of squamous cell carcinoma.

\section{Discussion}

SCC of the bladder is an uncommon primary malignancy of the bladder. Whilst chronic irritation, and chronic urinary tract infection are well known predisposing factors in Western populations, there is to date, no reported cases of bladder SCC secondary to fungal balls $\mathrm{s}^{2,3}$.

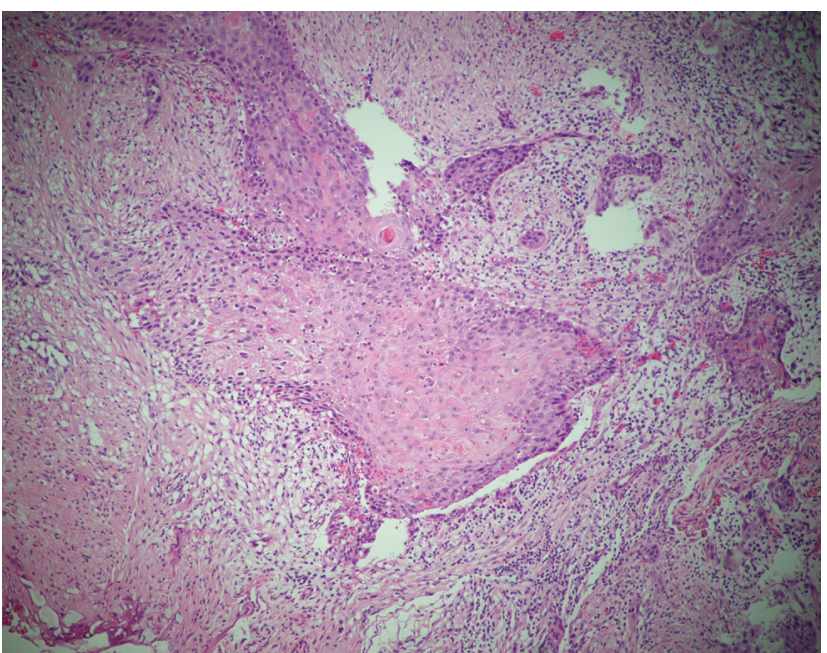

Figure 7. Haematoxylin and eosin stain, 100x magnification. Invasive carcinoma with squamous differentiation with inclusion of a keratin pearl.

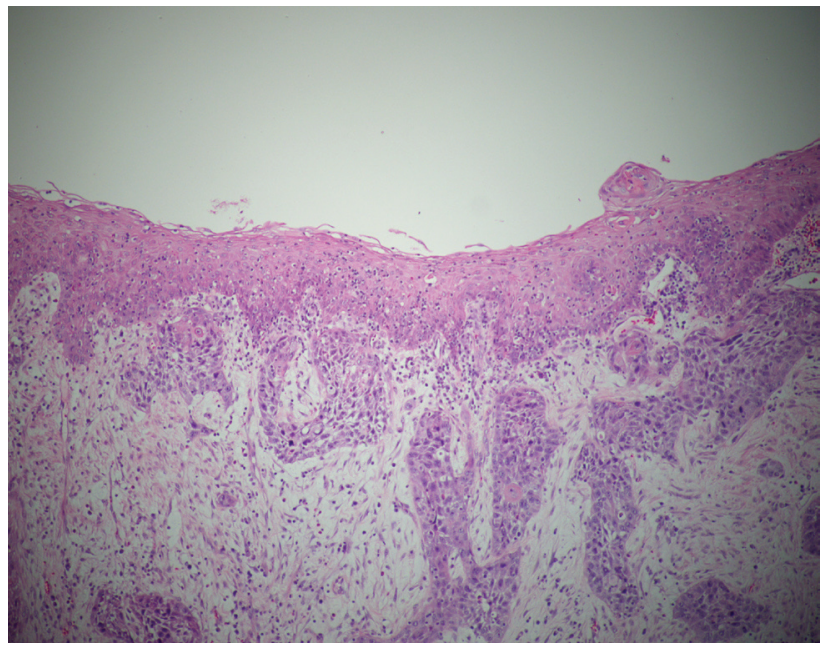

Figure 8. Haematoxylin and eosin stain, 100x magnification. Superficial squamous metaplasia without atypia is seen overlying SCC which has invaded the lamina propria.

SCC of the urinary tract typically presents at an advanced stage. In a large series of 1422 non-bilharzial SCC cases $85 \%$ were muscle invasive at diagnosis ${ }^{5}$. Additionally $56 \%$ of all bladder SCC were graded as American Joint Committee on Cancer (AJCC) stage T3 or $\mathrm{T} 4$ at diagnosis ${ }^{5}$.

SCC of the urinary tract has a significantly higher mortality than primary urothelial carcinoma, even after adjustment for higher tumour stage for SCC at diagnosis ${ }^{5}$. Scosyrev et al. found that for T4 tumours, even with cystectomy two year survival rates for SCC were low at $28 \%$, where-as for stage matched urothelial carcinoma survival was significantly improved at $42 \%$. Two year survival rates for T4 SCC without cystectomy is poor at only $5 \%$. 


\section{Conclusion}

We present, we believe, the first documented case of primary SCC of the bladder secondary to an upper tract fungal ball. Despite the patient being under close urological surveillance for her fungal ball at the time of tumour development, the cancer demonstrated transmural invasion at initial diagnosis and was surgically unresectable. The disease was rapidly progressive and the patient passed away fewer than four months following diagnosis.

\section{Consent}

Written informed consent for publication of their clinical details and clinical images was obtained from the patient's next of kin.
Author contributions

AK writing and literature review. BS provided histological images and contributed to article structure. AM helped in writing of the article and provided clinical images. AA concept of article and proofing of article. All authors have read and approved the final proof of this manuscript.

Competing interests

No competing interests were disclosed.

\section{Grant information}

The author(s) declared that no grants were involved in supporting this work.
1. Serretta V, Pomara G, Piazza F, et al:: Pure squamous cell carcinoma of the bladder in western countries. Report on 19 consecutive cases. Eur Urol. 2000; 37(1): 85-9. PubMed Abstract | Publisher Full Text

2. Locke JR, Hill DE, Walzer Y: Incidence of squamous cell carcinoma in patients with long-term catheter drainage. J Urol. 1985; 133(6): 1034-5. PubMed Abstract

3. Abol-Enein $\mathrm{H}$ : Infection: is it a cause of bladder cancer? Scand J Urol Nephrol Suppl. 2008; 42(218): 79-84.

PubMed Abstract | Publisher Full Text
4

Ghoneim MA, el-Mekresh MM, el-Baz MA, et al.: Radical cystectomy for carcinoma of the bladder: critical evaluation of the results in 1,026 cases. J Urol. 1997; 158(2): 393-9.

PubMed Abstract | Publisher Full Text

5. Scosyrev E, Yao J, Messing E: Urothelial carcinoma versus squamous cell carcinoma of bladder: is survival different with stage adjustment? Urology. 2009; 73(4): 822-7.

PubMed Abstract | Publisher Full Text 


\section{Open Peer Review}

\section{Current Peer Review Status:}

\section{Version 1}

Reviewer Report 07 October 2015

https://doi.org/10.5256/f1000research.6764.r10705

C 2015 Ablin R. This is an open access peer review report distributed under the terms of the Creative Commons Attribution License, which permits unrestricted use, distribution, and reproduction in any medium, provided the original work is properly cited.

\section{Richard J Ablin}

Department of Pathology, University of Arizona College of Medicine, The Arizona Cancer Center and BIO5 Institute, Tucson, AZ, 85724, USA

This is an interesting Case Report, particularly relative from the aspect of implications of fungi, their mycotoxins and a possible role in malignancy, e.g., See: Kaufmann et al. Oncology News, 9, 164-66, 2014, and references therein.

Given the implications, it is surprising the authors did not do more of a thorough infectious disease workup, whereby the patient's compromised physiological status may have made her vulnerable to kidney and bladder infections. It is reasonable that whereby, their use of catheters, the fungus may have arisen from a contaminated catheter. The latter begs the question as to why the authors' did not identify the fungus?

Competing Interests: No competing interests were disclosed.

I confirm that I have read this submission and believe that I have an appropriate level of expertise to confirm that it is of an acceptable scientific standard, however I have significant reservations, as outlined above.

Author Response 13 Oct 2015

Andrew Keller, Ipswich General Hospital, Ipswich, Australia

Thanks Dr. Ablin for your review and comments. It is indeed a glaring omission that I did not include the cultured fungus in the report. The cultures all grew candida albicans, which was broadly sensitive to all tested anti-fungal agents at low minimum inhibitory concentrations.

Whilst it is acknowledged that urinary tract instrumentation precipitated many of her septic episodes, her presenting complaint of recurrent poly-microbial urinary tract infections and 
renal pelvis mass (which on investigation was revealed to be a fungal ball) occurred in the absence of previous urinary tract instrumentation.

The location of her tumour was exactly where the vesical loop of the ureteric stent would have been situated. This does make me suspect that the ureteric stent, via chronic inflammation from both stent colonization and mechanical irritation, was contributory to her carcinogenesis.

Competing Interests: No competing interests were disclosed.

Reviewer Report 16 July 2015

https://doi.org/10.5256/f1000research.6764.r8953

(C) 2015 Ather H. This is an open access peer review report distributed under the terms of the Creative Commons Attribution License, which permits unrestricted use, distribution, and reproduction in any medium, provided the original work is properly cited.

\section{Hammad Ather}

Section of Urology, Aga khan University, Karachi, Pakistan

This is an interesting case as it shows a rather dramatic development and progression of squamous cell cancer of the bladder.

I have few observations on this submission.

1. In retrospect were there any observation on the part of bladder which subsequently showed any changes like hyperemia?

2. The CT showed no evidence of T4 disease, however the per operative findings were quite different. What was the time frame between the CT and surgery?

Competing Interests: No competing interests were disclosed.

I confirm that I have read this submission and believe that I have an appropriate level of expertise to confirm that it is of an acceptable scientific standard.

Author Response 02 Aug 2015

Andrew Keller, Ipswich General Hospital, Ipswich, Australia

Thanks for your comments Dr. Ather.

1. Retrospectively there were some erythematous patches over the area prior to the initial resection but the erythema was not limited to only that area. They were assumed to be a reaction to the chronic cystitis this lady experienced secondary to her fungal ball. 
2. The time frame between the CT which demonstrated the mass, and the attempted cystectomy was just over five weeks. Cystectomy was attempted just under four weeks after initial tissue confirmation of SCC via TURBT. Due to the patients extensive medical history some of the delay was due to the necessary anaesthetic work-up in order to establish her fitness for surgery.

Competing Interests: No competing interests were disclosed.

The benefits of publishing with F1000Research:

- Your article is published within days, with no editorial bias

- You can publish traditional articles, null/negative results, case reports, data notes and more

- The peer review process is transparent and collaborative

- Your article is indexed in PubMed after passing peer review

- Dedicated customer support at every stage

For pre-submission enquiries, contact research@f1000.com 